\title{
Multiple sclerosis: correlation of magnetic resonance imaging with cerebrospinal fluid findings
}

\author{
LAWRENCE S HONIG, * RENUKA SIDDHARTHAN, * WILliAM A SHEREMATA, \\ J J SHELDON, $\dagger$ ALAN SAZANT*
}

From the Department of Neurology, ${ }^{*}$ University of Miami School of Medicine, Miami, FL, and the Department of Radiology, $\dagger$ Mount Sinai Medical Center, Miami Beach, FL, USA

SUMMARY MRI examination of 41 patients with clinical definite multiple sclerosis showed white matter lesions of high proton $\mathrm{T}_{2}$ signal consistent with demyelination in $76 \%$ and CSF abnormalities present in $76 \%$. Of patients with CSF abnormalities, $26 \%$ had normal MRI scans; conversely $26 \%$ of patients with MRI abnormalities had negative CSF studies. Thus a significant number of multiple sclerosis patients had negative results on either MRI or CSF examination, while only $5 \%$ had normal results on both tests.

Diagnosis of multiple sclerosis depends primarily on clinical history and neurological examination. Signs and symptoms attributable to at least two central nervous system lesions must occur in two or more separate attacks of remitting neurological dysfunction (or, a progressive course of at least 6 months' duration). ${ }^{1}$ Explanations other than demyelinating disease must be ruled out. ${ }^{12}$ Advantage may be made of "paraclinical" studies ${ }^{2}$ such as contrast-enhanced computed tomography $(\mathrm{CT}),^{3-7}$ magnetic resonance imaging (MRI), ${ }^{6-22}$ or cerebrospinal fluid (CSF) analysis, ${ }^{23-29}$ as well as evoked responses, $29-31$ urodynamic $^{32}$ or neuropsychologic evaluations. ${ }^{33} 34$

MRI of the brain is superior to CT in demonstrating the white matter lesions of multiple sclerosis. ${ }^{6-22}$ Sensitivity of MRI is greatest when using $T_{2}$ weighted images acquired by spin-echo sequences with relatively long repetition (TR) and echo (TE) times; ${ }^{11-131722}$ although images with extreme $T_{2}$ weighting decrease parenchymal contrast and obscure periventricular white matter involvement because of intense signal from ventricular CSF. Multiple sclerosis lesions consist most frequently of areas of high $\mathrm{T}_{2}$ signal in the periventricular and supraventricular white matter, often in the atria, or genu of the occipi-

Address for reprint requests: Dr Lawrence S Honig, Department of Neurology (C-338/RES), Stanford University Medical Center, Stanford, CA 94305-5235, USA.

Received 8 May 1987 and in revised form 26 August 1987. Accepted 29 August 1987 tal and frontal horns; involved other regions include internal capsule, centrum semiovale, cerebellum, and brainstem (notably pons). Several MRI grading scales for multiple sclerosis have been developed. ${ }^{132022} \mathrm{We}$ use that of Runge et $\mathrm{al}^{13}$ with score 0 to 4 according to the extent and distributions of the lesions. We report here dual examination by both MRI and CSF analysis of patients with definite multiple sclerosis of varying disability and disease duration, to determine the relative usefulness of these two tests.

\section{Materials and methods}

Our study group consisted of 41 patients (30F/11M) from the University of Miami Multiple Sclerosis Clinic with áverage age $39 \cdot 4 \pm 10$ (SD) yr (range 22-62). Diagnosis of 'clinically definite multiple sclerosis was established by the criteria of Schumacher et al. ${ }^{1}$ Mean duration of disease was $7 \cdot 4 \pm 6.5$ y (range 1-24). Each patient was evaluated by the Kurtzke Disability Status Scale ${ }^{35}$ (DSS, mean $3 \cdot 8 \pm 2 \cdot 6$, range $1-8$ ), and by lumbar puncture. The presence of CSF oligoclonal banding, ${ }^{2428}$ increased IgG $(>5.5 \mathrm{mg} / \mathrm{dl}), \mathrm{IgG}$ percentage of total protein $(>10.5 \%)$, or increased myclin basic protein $(>6 \mathrm{ng} / \mathrm{ml})$ was interpreted as abnormal. ${ }^{23-29}$ CSF IgG Index and IgG SYN were determined ${ }^{25-27}$ when possible; these derived results did not change any CSF diagnosis.

MRI was performed with a Siemens Magnetom $(0.35$ Tesla), using a spin-echo acquisition sequence of $\mathrm{TR}=1500 \mathrm{~ms}$ with dual echo delays of TE $=35$ and $70 \mathrm{~ms}$ and a $256 \times 256$ matrix. Axial images were obtained in two interlaced sets of seven slices, $10 \mathrm{~mm}$ thick with $10 \mathrm{~mm}$ interspacing. ${ }^{16}$ Films were reviewed without knowledge of the 
patients' clinical classification and graded on a scale of 0 (normal scan), or 1 to 4 using the Vanderbilt criteria of Runge et al. ${ }^{13}$

\section{Results}

MRI Examination Periventricular and white matter lesions were visualised by MRI in 76\% (31/41) of patients (table 1). There was a significant trend ( $p=0.006$ by Mann-Whitney test) for positive MRI to be found in patients of longer duration illness: only $45 \%(5 / 11)$ of patients with less than 3 years illness had abnormal MRI while $87 \%(26 / 30)$ of those with duration of multiple sclerosis greater than 3 years showed positive MRI findings (table 1). Mean duration of disease in patients with negative MRI findings $(3.4 \pm 2.8$ yr $)$ differed significantly $(F[1,39]=5.6 ; p<0.02)$ from patients with positive MRI findings $(8 \cdot 7 \pm 6.9 \mathrm{yr})$. Comparison of those $24 \%$ of patients with normal MRI with those showing abnormal imaging exams did not however show any significant differences in age $(36 \pm 10$ vs $41 \pm 10)$, sex $(80 \% \mathrm{~F}$ vs $71 \% \mathrm{~F})$, age of onset $(33 \pm 9$ vs $32 \pm 10)$, or DSS $(3 \cdot 8 \pm 2 \cdot 7$ vs $3 \cdot 8 \pm 2 \cdot 6)$. In addition, there was poor correlation ( $\mathrm{r}=0.11$; $\mathrm{p}>0.05)$ between Vanderbilt grade of brain MRI and DSS.

CSF Analysis An increase in CSF IgG, MBP and/or oligoclonal CSF banding was noted in $76 \%(31 / 41)$ of patients (table 1). Of these patients with abnormal CSF, $80 \%(25 / 31)$ had elevated IgG as percentage of total protein, while $10 \%$ (3) were classified as abnormal only on the basis of increased MBP, and another $10 \%$ (3) only by the presence of oligoclonal banding. There was no significant (all $p>0.05$ ) correlation of CSF abnormalities to patient age, sex, age at multiple sclerosis onset, MRI grade, duration of illness, or DSS score, although there was a slight trend with the latter two.

Comparison of CSF and MRI findings The paired MRI and CSF results were examined for each patient, and summarised in table 2 . Among patients with abnormal MRI examinations, $26 \%$ were without demonstrable CSF abnormalities. Conversely, of patients with CSF abnormalities, $26 \%$ had negative MRI studies. The CSF study and MRI examination results were both abnormal in $56 \%(23 / 41)$ of patients. Only $5 \%(2 / 41)$ of study patients with clinically
Table 2 Correlation of paired MRI and CSF findings in multiple sclerosis patients

\begin{tabular}{lcccc}
\hline & & & $M R I$ & \\
& {$[-]$} & {$[+]$} & Total \\
\hline & {$[-]$} & 2 & 8 & 10 \\
$S$ & & $(5 \%)$ & $(20 \%)$ & $(24 \%)$ \\
$S$ & {$[+]$} & 8 & 23 & 31 \\
$F$ & & $(20 \%)$ & $(56 \%)$ & $(76 \%)$ \\
& Total & 10 & 31 & 41 \\
& & $(24 \%)$ & $(76 \%)$ & $(100 \%)$ \\
\hline
\end{tabular}

[-]: no abnormalities present

[+]: abnormalities present

definite multiple sclerosis had MRI and CSF examinations both normal.

\section{Discussion}

Magnetic resonance imaging detected abnormal areas of increased proton $\mathrm{T}_{2}$ signal in a high proportion (76\%) of our multiple sclerosis patients. While some initial reports of MRI in selected patients indicated aberrant findings in nearly $100 \%$ of patients with clinically definite multiple sclerosis 810111318 the patients in such studies mostly had florid disease of long duration. More recent studies ${ }^{71619}$ suggested 76-85\% of clinically definite multiple sclerosis patients have abnormal MRI findings.

MRI of the brain showed no abnormalities in a significant proportion $(24 \%)$ of our patient group, mostly those early in the course of disease. The $a b$ sence of cerebral findings by MRI, despite clinical disease (and abnormal CSF in eight of these 10 patients) might be due to mild, diffuse infiltration, limited disturbances of the blood-brain barrier or small lesions below present spatial resolution limits (several mm). Technical improvements in signal/noise ratio and resolution should increase MRI image quality, and the use of paramagnetic contrasting agents may allow MRI evaluation of barrier dysfunction. ${ }^{36}$ However, some normal brain MRI examinations probably accurately reflect an absence of cerebral involvement. A number of clinically definite multiple sclerosis patients are without cerebral pathology at necropsy, ${ }^{37}$ or by MRI (Honig and Sheremata, in preparation), the result of demyelination exclusively in the spinal cord, for which MRI surface coil tech-

Table 1 Abnormal MRI and CSF findings in relation to duration of disease

\begin{tabular}{|c|c|c|c|c|}
\hline MS duration (years) & VGS average & Abnormal MRI No. (\%) & Abnormal CSF No. (\%) & Total No. patients \\
\hline $\begin{array}{c}0-3 \\
3-6 \\
6-12 \\
12-30\end{array}$ & $\begin{array}{l}1.7 \pm 2.0 \\
2.5 \pm 1.6 \\
2.3 \pm 1.4 \\
3.0 \pm 0.7\end{array}$ & $\begin{array}{r}5(45) \\
11(79) \\
6(86) \\
9(100)\end{array}$ & $\begin{array}{r}7(64) \\
13(93) \\
5(71) \\
6(67)\end{array}$ & $\begin{array}{r}11 \\
14 \\
7 \\
9\end{array}$ \\
\hline $0-30$ & $2 \cdot 4 \pm 1 \cdot 6$ & 31 (76) & $31(76)$ & 41 \\
\hline
\end{tabular}

VGS = Vanderbilt MRI Grading Scale; means \pm standard deviations. 
nology is providing higher sensitivity. The poor correlation between MRI grade and DSS also probably reflects that most DSS disability is a function of spinal cord rather than cerebral involvement.

We observed a correlation of the frequency of high $T_{2}$ signal MRI lesions with duration of multiple sclerosis. Of our 30 patients with multiple sclerosis of longer than 3 years duration, $87 \%$ had positive brain MRI examinations, while negative findings on MRI were significantly related to shorter duration of disease (although not to DSS, age of onset, or sex). Of the 10 patients with normal MRI exams, eight $(80 \%)$ had duration of illness of less than 4 years, compared with $29 \%$ of the 31 patients with positive, abnormal scans $\left(\chi^{2}=6.13, p<0.02\right)$. The increasing incidence of positive MRI findings with duration of disease is consistent with our observations (unpublished results) and others that while lesions of multiple sclerosis seen by MRI may fluctuate in size they do not disappear. $^{1538}$

Cerebrospinal fluid was abnormal in $76 \%$ of our patient group. Prior reports identify increased IgG in $73-90 \%$ of definite multiple sclerosis cases. ${ }^{24262829}$ Different CSF indices are of comparable sensitivity, but of varied advantage in specificity, variability and relevance to blood-brain barrier dysfunction. 24-27 Normalised CSF IgG in the form of the dimensionless IgG index ${ }^{24-27}$ or the quantitative IgG SYN ${ }^{1623}$ correct for loss of barrier integrity. However, in our patient group neither of these computed values increased CSF exam sensitivity. Oligoclonal bands in CSF are not as specific for multiple sclerosis, but have been reported present in $85-95 \%$ of cases and may be present in the face of normal CSF IgG. ${ }^{23}$ Reports conflict on relation of CSF findings to the timing of lumbar puncture with respect to disease exacerbation. ${ }^{242829}$ CSF results probably vary more with clinical status than MRI results.

Brain MRI and CSF examinations showed approximately equal sensitivity $(76 \%)$ in detecting disease in our group of patients with definite multiple sclerosis. MRI may be valuable in providing objective anatomical evidence of disease activity, by monitoring lesion number or size. ${ }^{13151638}$ However, some $20 \%$ of the patients had normal examinations by MRI but had abnormal findings on CSF study. Significant numbers of patients diagnosed as having definite multiple sclerosis may lack confirmatory laboratory findings if only MRI imaging, or CSF analysis, is performed. The frequency of negative findings on MRI examination may be greatest early in the course of disease.

We thank Dr Stella De Fortuna for assistance with the CSF examinations, and Dr W W Tourtellotte for his critical comments on the manuscript. This study was supported in part by NIH Training Grant NS 07238.
References

1 Schumacher GA, Beebe G, Kibler RF, et al. Problems of experimental trials of therapy in multiple sclerosis: report by the panel on the evaluation of experimental trials of therapy in multiple sclerosis. Ann NY Acad Sci 1965;122:552-68.

2 Poser CM, Paty DW, Scheinberg L, et al. New diagnostic criteria for multiple sclerosis: guidelines for research protocols. Ann Neurol 1983;13:227-31.

3 Cala LA, Mastaglia FL, Black JL. Computerized tomography of brain and optic nerve in multiple sclerosis: observations in 100 patients including serial studies in 16. J Neurol Sci 1978;36:411-26.

4 Hershey LA, Gado MH, Trotter JL. Computerized tomography in the diagnostic evaluation of multiple sclerosis. Ann Neurol 1979;5:32-39.

5 Barrett L, Drayer B, Shin C. High-resolution computerized tomography in multiple sclerosis. Ann Neurol 1985;17:33-38.

6 Bradley WG, Waluch V, Yadley RA, Wycoff RR. Comparison of $C T$ and $M R$ in 400 patients with suspected disease of the brain and cervical spinal cord. Radiology 1984;152:695-702.

7 Jacobs L, Kinkel WR, Polachini I, Kinkel RP. Correlations of nuclear magnetic resonance imaging, computerized tomography, and clinical profiles in multiple sclerosis. Neurology 1986;36:27-34.

8 Young IR, Hall AS, Pallis CA, Legg NJ, Bydder GM, Steiner RE. Nuclear magnetic resonance imaging of the brain in multiple sclerosis. Lancet 1981;2:1063-6.

9 Bydder GM, Steiner RE, Young IR, et al. Clinical NMR imaging of the brain: 140 cases. $A J R$ 1982;139:215-36.

10 Lukes SA, Crooks LE, Aminoff MJ, et al. Nuclear magnetic resonance imaging in multiple sclerosis. Ann Neurol 1983;13:592-601.

11 Brant-Zawadzki M, Davis PL, Crooks LE, et al. NMR demonstration of cerebral abnormalities: comparison with CT. AJR 1983;140:847-54.

12 Young IR, Randell CP, Kaplan PW, James A, Bydder GM, Steiner RE. Nuclear magnetic resonance (NMR) imaging in white matter disease of the brain using spin-echo sequences. J Comput Assist Tomogr 1983;7:290-4.

13 Runge VM, Price AC, Kirshner HS, Allen JH, Partian CL, James AE. Magnetic resonance imaging of multiple sclerosis: A study of pulse-technique efficacy. AJR 1984;143:1015-26.

14 Maravilla KR, Weinreb JC, Suss R, Nunnally RL. Magnetic resonance demonstration of multiple sclerosis plaques in the spinal cord. AJNR 1984;5:685-9.

15 Johnson MA, Li DK, Bruany DJ, Payne JA. Magnetic resonance imaging: Serial observation in multiple sclerosis. AJNR 1984;5:495-9.

16 Sheldon JJ, Siddharthan R, Tobias J, Sheremata WA, Soila K, Viamonte M Jr. Magnetic resonance imaging of multiple sclerosis: Comparison with clinical, paraclinical, laboratory and CT examination. AJNR 1985;6:683-90.

17 Baker HL, Berquist TH, Kispert DB, et al. Magnetic resonance imaging in a routine clinical setting. Mayo Clin Proc 1985; 60:75-90.

18 Baumhefner RW, Tourtellotte WW, Ellison G, et al. Multiple sclerosis: correlation of magnetic resonance imaging (MRI) with clinical disability, quantitative evaluation of neurologic function (QENF), evoked potentials and intra-blood-brainbarrier (BBB) IgG synthesis. Neurology 1986;36(Suppl 1):283.

19 Paty DW, Hashimoto SA, Hooge $\mathrm{H}$, et al. Magnetic resonance imaging (MRI) in multiple sclerosis (MS): a prospective evaluation of usefulness in diagnosis. Neurology 1986;36(Suppl 1): 186.

20 Edwards KR, Farlow MR, Stevens JC. Multiple sclerosis: MRI and clinical correlation. AJNR 1986;7:595-8.

21 Smith AS, Weinstein MA, Modic MT, et al. Magnetic resonance with marked T2-weighted images: improved demonstration of brain lesions, tumor, and edema. AJNR 1985;6:691-7. 
22 Stevens JC, Farlow MR, Edwards, MK, Yu P. Magnetic resonance imaging: clinical correlation in 64 patients with multiple sclerosis. Arch Neurol 1986;43:1145-48.

23 Johnson KP. Cerebrospinal fluid and blood assays of diagnostic usefulness in multiple sclerosis. Neurology 1980;30:106-9.

24 Lauer $\mathrm{K}$. On the diagnostic value of different CSF investigations in multiple sclerosis. $J$ Neurol 1984;231:130-4.

25. Whitaker JN. Quantitation of the synthesis of immunoglobulin G within the central nervous system. Ann Neurol 1985;17:11-12.

26 Tourtellotte WW, Staugaitis SM, Walsh MJ, et al. The basis of intra-blood-brain-barrier IgG synthesis. Ann Neurol 1985;17:21-27.

27 Lefvert AK, Link H. IgG production within the central nervous system: a critical review of proposed formulae. Ann Neurol 1985;17:13-20.

28 Link H, Muller R. Immunoglobulins in multiple sclerosis and infections of the nervous system. Arch Neurol 1971;25:326-44.

29 Bartel DR, Markand ON, Kolar OJ. The diagnosis and classification of multiple sclerosis: evoked responses and spinal fluid electrophoresis. Neurology 1983;33:611-7.

30 Chiappa KH. Pattern shift visual, brain stem auditory and short latency somato-sensory evoked potentials in multiple sclerosis. Neurology 1980;30:110-23.

31 Cohen SN, Syndulko K, Tourtellotte WW. Visual evoked potentials in the diagnosis of multiple sclerosis. In: Poser CM, Paty
DW, Scheinberg L, McDonald WI, Ebers GC, eds. The Diagnosis of Multiple Sclerosis. New York: Thieme-Stratton, 1984:103-119.

32 Bradley WE, Logothetis JL, Timm GW. Cystometric and sphincter abnormalities in multiple sclerosis. Neurology 1973;23:1131-9.

33 Peyser JM, Edwards KR, Poser CM, Filskow SB. Cognitive function in patients with multiple sclerosis. Arch Neurol 1980;37: 577-9.

34 Heaton RK, Nelson LM, Thompson DS, Burks JS, Franklin GM. Neuropsychological findings in relapsing-remitting and chronic-progressive multiple sclerosis. J Consult Clin Psychol 1985;53:103-10.

35 Kurtzke JF. Further notes on disability evaluation in multiple sclerosis, with scale modifications. Neurology 1965;15:654-61.

36 Runge VM, Clanton JA, Lukehart GM, Partain CL, James AE Jr. Paramagnetic agents for contrast-enhanced NMR imaging: a review. AJR 1983;141:1209-15.

37 Ikuta F, Zimmerman HM. Distribution of plaques in seventy autopsy cases of multiple sclerosis in the United States. Neurology 1976;26(Supp.):26-8.

38 Paty DW, Isaac VD, Grochowski E, et al. Magnetic resonance imaging (MRI) in multiple sclerosis (MS): a serial study in relapsing and remitting patients with quantitative measurements of lesion size. Neurology 1986;36(Suppl 1):177. 